\title{
ON THE ELECTROLYTIC DEPOSITION OF METALS FROM NON-AQUEOUS SOLUTIONS
}

\section{BY LOUIS KAHLENBERG}

In connection with my researches on the differences of potential between metals and non-aqueous solutions of their salts ${ }^{\mathrm{I}}$ it was necessary to ascertain whether Faraday's law holds for such solutions, before attempting to apply Nernst's formula for calculating the E. M. F. of the galvanic chains investigated. A series of electrolytic determinations was consequently made, the results of which are of general interest because little or nothing has hitherto been done on the electrolytic deposition of the metals from other than aqueous solutions at ordinary temperatures. The reason for this probably lies in the fact that it is commonly supposed that non-aqueous solutions do not conduct electricity sufficiently to admit of electrolytic determinations.

The general plan of experimentation was as follows: A known quantity of anhydrous salt was dissolved in a definite amount of anhydrous solvent. This solution was then electrolyzed, using a platinum cathode and an anode of the same metal whose salt the solution contained. The difference of potential between the electrodes was ascertained in each case, as was also the area of the cathode. The amount of metal deposited was compared with the silver separated out in a silver voltameter that was placed in the same circuit. The voltameter, of course, also indicated the strength of the current used. An aqueous solution of silver nitrate $I$ to 7 was used in the voltameter. The temperature of experiment was about $20^{\circ} \mathrm{C}$ unless otherwise stated.

I Jour, Phys. Chem. 3, 379 (1899). 
A $n$ / o solution of silver nitrate in pyridine when thus electrolyzed for one and one-fourth hours, using a difference of potential of two volts between the electrodes and a cathode of $\mathrm{r} 5 \mathrm{sq} \mathrm{cm}$ area, yielded a deposit of $0.3827 \mathrm{~g}$ silver. The deposit in the voltameter weighed $0.3849 \mathrm{~g}$. In another experiment, the same solution was electrolyzed for one hour, using a pressure of two volts and a cathode having an area of $60 \mathrm{sq} \mathrm{cm}$. The deposit weighed $0.78 \mathrm{rg} \mathrm{g}$; that in the voltameter weighed $0.7836 \mathrm{~g}$. In each case the deposit from the pyridine solution was white, firm, compact, well adhering, and susceptible to polish. It was then not unlike the deposits obtained from the cyanide solutions commonly used in silver plating.

A $n /$ Io solution of silver nitrate in aniline was electrolyzed for five hours, the cathode area being $60 \mathrm{sq} \mathrm{cm}$ and the difference of potential between the electrodes two volts. The silver deposited weighed $0.1780 \mathrm{~g}$, while that separated out in the voltameter weighed $0.1788 \mathrm{~g}$. The deposit from the aniline solution was white, dense, and well adhering.

Silver nitrate in benzonitrile ( $0.85^{8} 5 \mathrm{~g}$ in ro $\mathrm{cc}$ ) was electrolyzed for thirty-four minutes, using an E. M. F. of 1.9 volts and a cathode of $15 \mathrm{sq} \mathrm{cm}$ area. The silver deposited was white, firm, dense, and well adhering. It weighed $0 . \pi 603 \mathrm{~g}$, while that deposited in the voltameter weighed o. I6I2 g.

A saturated solution of silver nitrate in quinoline was electrolyzed for four and one-quarter hours, employing an E.M. F. of two volts and a cathode having an area of $60 \mathrm{sq} \mathrm{cm}$. The deposit weighed $0.245^{2} \mathrm{~g}$, while that in the voltameter weighed $0.2501 \mathrm{~g}$. The silver deposited from the quinoline solution appears very dark at first, owing to the presence on it of carbonaceous decomposition products from the quinoline. The deposit after being washed with alcohol and strongly heated turns white.; it is firm, compact, and well adhering. The appearance of the carbonaceous material on the silver indicates that a complicated reaction takes place at the cathode to a certain extent. To this the fact that the silver deposited weighed appreciably less than that thrown down in the voltameter is very likely to be ascribed. 
A solution of lead nitrate in pyridine, containing $4.4335 \mathrm{~g}$ of the salt in $50 \mathrm{cc}$, was subjected to electrolysis at $50^{\circ} \mathrm{C}$ for five hours and seventeen minutes, using a cathode $15 \mathrm{sq} \mathrm{cm}$ in area and an E. M. F. of three volts. The deposit was grayish, well adhering, and weighed $0.073^{2} \mathrm{~g}$. The silver in the voltameter weighed $0.0745 \mathrm{~g}$, which is equivalent to $0.07 \mathrm{I} 4 \mathrm{~g}$ lead. The solution is a very poor conductor as is evident from the slight deposit obtained.

A fourteen percent solution of antimony trichloride in methyl alcohol was electrolyzed for one hour, using a cathode of $20 \mathrm{sq} \mathrm{cm}$ area and an E. M. F. of 1.8 volts. The antimony, which was deposited in bright, not very well adhering crystals, weighed $0.2239 \mathrm{~g}$; while the silver precipitated in the voltameter weighed $0.6156 \mathrm{~g}$, which is equivalent to $0.2280 \mathrm{~g}$ antimony. In the second experiment, which was run for two hours and sixteen minutes under the same conditions as above, except that an extra resistance was introduced into the circuit, $0.2146 \mathrm{~g}$ of antimony was deposited and $0.5915 \mathrm{~g}$ silver was separated out in the voltameter, the latter amount being equivalent to $0.2192 \mathrm{~g}$ antimony. In this case, the antimony deposited was also crystalline and did not adhere very well. Several attempts to secure a good deposit of bismuth from a solution of bismuth trichloride in methyl alcohol failed, a black, spongy, poorly adhering mass being invariably obtained.

From a saturated silver nitrate solution in acetone, a dense, white, firmly adhering deposit may be obtained, but the solution conducts so very poorly that no quantitative determinations were made. It will be noted that, except in the case of the lead deposited from the solution of lead nitrate in pyridine, the silver separated out in the voltameter is somewhat larger in amount than it should be to conform strictly to Faraday's law. The most notable discrepancy occurs in the case of the quinoline solution which has already been discussed. The silver nitrate solution used in the voltameter was one that had been repeatedly employed; and according to Rodger and Watson, ${ }^{\mathrm{I}}$ such solutions

'Rodger and Watson: Phil. Trans. 186A, 63I (1895). 
give deposits that are somewhat too heavy. The silver deposits obtained from the silver nitrate solutions in pyridine, benzonitrile, and aniline were somewhat brownish in color when first taken from the solutions; only after being washed with alcohol and heated did they assume the fine white appearance. Now this brownish discoloration was not as great as in the case of the quinoline solutions; but nevertheless it indicated that, like in the latter, the solvents had suffered some decomposition. It is to these slight side reactions that I am inclined to ascribe in the main the fact that a little less metal was deposited in the electrolytic cell than there ought to have been, according to the weight of the silver thrown down in the voltameter placed in the same circuit. The antimony deposited from the solution of antimony trichloride in methyl alcohol was perfectly bright and there were no indications whatever of side reactions; nevertheless it will be noted that in both of the experiments above described, the antimony deposited is not quite equivalent to the silver obtained in the voltameter. As the two separate determinations agree fairly well, I shall content myself with the presentation of the results obtained, adding simply that the antimony used was a so-called C. P. sample obtained in the market and was not further tested as to its purity.

Aside from the minor discrepancies alluded to, the results recorded taken in general; go to show that Faraday's law does hold for non-aqueous solutions. The work done thus far is to be considered as preliminary in character.

The question arose, can silver nitrate be completely deposited from a silver nitrate solution in pyridine by using two platinum electrodes, and if so, under what conditions? It would also be of interest to know whether silver can be completely deposited in compact form from a solution of silver nitrate in pyridine plus water, and under what conditions. The investigation of these questions was undertaken in this laboratory by Mr. W. C. Sieker, and the results that were obtained are given in the following table, the headings of which are self-explanatory. All the determinations were made at room temperatures (about $20^{\circ} \mathrm{C}$ ). 


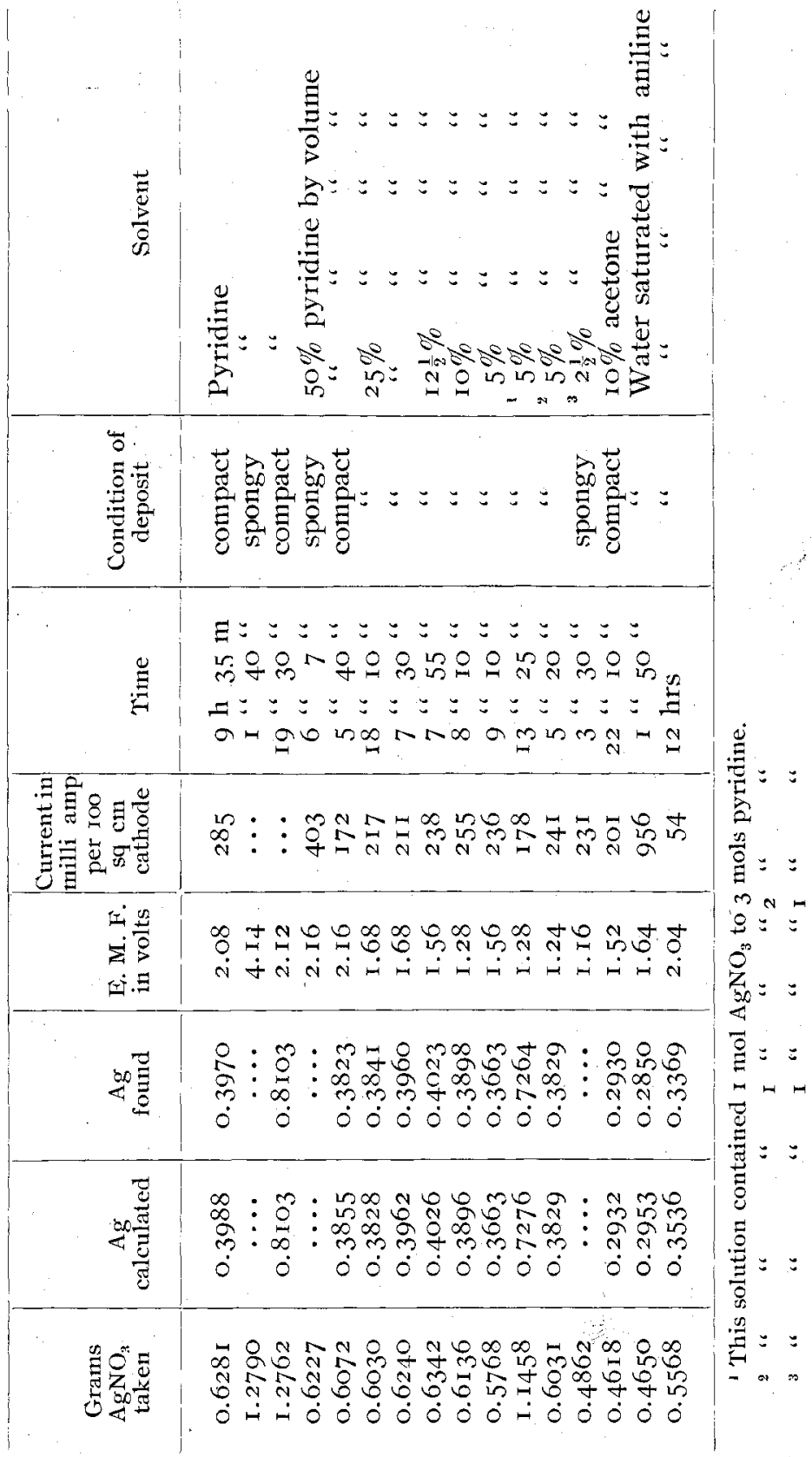


The solutions electrolyzed usually had a volume of about $50 \mathrm{cc}$. The times do not indicate the minimum time required to throw down all the silver. Owing to the press of other work, the experiments usually were allowed to run longer than was actually necessary.

It will be observed from the table that silver can be com. pletely deposited in compact form from a silver nitrate solution in pyridine. The potential used should be about three volts and the current density about 0.3 ampere per IOO sq cin cathode area. Again, silver can be completely deposited in dense, white form from a silver nitrate solution in pyridine, plus water, providing that at least two molecules of pyridine are present to one of silver nitrate. Good results are obtained when employing an E. M. F. of I.24 to 2.I 6 volts, and a current density of from 0.17 to 0.25 ampere per $100 \mathrm{sq} \mathrm{cm}$ cathode area. The table also shows that silver may be deposited in a dense, compact form, quantitatively from a silver nitrate solution in a solvent consisting of nine volumes of water and one volume of acetone. Finally, when silver nitrate is dissolved in water previously saturated with aniline, the deposit that is obtained upon electrolysis is not crystalline, but dense and compact. The quantitative results obtained with the two solutions tested were not very satisfactory as the table shows. On standing, the aniline gradually reduces the silver nitrate. This process is of course very much accelerated when the solution is exposed to the light.

Laboratory of Physical Chemistry,

University of Wisconsin. Madison. 